\title{
When Realism Made a Difference: The Constitution of Matter and its Conceptual Enigmas in Late 19th Century Physics
}

\author{
Torsten Wilholt \\ Department of Philosophy, Bielefeld University, P.O. Box 100131, D-33501 Bielefeld, Germany \\ E-mail: twilholt@uni-bielefeld.de
}

[Manuscript version. The original article is forthcoming in Studies in History and Philosophy of Modern Physics and will be available at http://www.sciencedirect.com/science/journal/13552198.]

\begin{abstract}
The late 19th century debate among German-speaking physicists about theoretical entities is often regarded as foreshadowing the scientific realism debate. This paper brings out differences between them by concentrating on the part of the earlier debate that was concerned with the conceptual consistency of the competing conceptions of matter-mainly, but not exclusively, of atomism. Philosophical antinomies of atomism were taken up by Emil Du Bois-Reymond in an influential lecture in 1872. Such challenges to the consistency of atomism had repercussions within the physics community, as can be shown for the examples of Heinrich Hertz and Ludwig Boltzmann. The latter developed a series of counter-arguments, culminating in an ingenious attempt to turn the tables on the critics of atomism and prove the inconsistency of non-atomistic conceptions of nature. Underlying this controversy is a disagreement over specific goals of physical research which was considered crucially relevant to the further course of physical inquiry. It thereby exemplifies an attitude towards the realism issue that can be contrasted with a different, more neutral attitude of regarding the realism issue as merely philosophical and indifferent with respect to concrete research programs in physics, which one also occasionally finds expressed in the 19th century controversy and which may be seen as the prevailing attitude of the 20th century debate.
\end{abstract}

Keywords: realism, atomism, antinomies, Du Bois-Reymond, Boltzmann

\section{Introduction}

In late 19th century physics, especially in the German-speaking countries, a long and persistent debate about what we now call theoretical entities unfolded. ${ }^{1}$ Some physicists (including Ernst Mach, Wilhelm Ostwald and Gustav Kirchhoff) sought to eliminate from physical theory all elements that they considered mere hypothetical constructs. They advocated a physics without pictures, which meant that descriptions

\footnotetext{
${ }^{1}$ See Howard, forthcoming, for an overview of the debate and its context.
} 
in terms of directly measurable quantities were in principle preferable. Others argued that physics without pictures was impossible, but conceded that physical pictures were not in exact correspondence to nature, but would only bear a partial resemblance to the phenomena. (This line of thought was elaborated by Heinrich Hertz and Ludwig Boltzmann and is related to earlier ideas by Hermann von Helmholtz.)

These controversies are generally regarded as foreshadowing the scientific realism debate in 20th century philosophy of science. (Cf. Popper 1956, Nagel 1961, p. 118 f., Niiniluoto 2002, chap. 1, to name just a few prominent examples.) This appraisal often explicitly includes those parts of the debate that were concerned with atomism and the argumentative efforts of atomism's most fervent advocate, Ludwig Boltzmann. (See, e.g., Nye 1976, Blackmore 1999.) My aim in this paper is to highlight a side of the debate which Boltzmann and others were involved in that is seldom discussed, viz., the concerns about the conceptual consistency of atomism. I want to accentuate the fact that an important concern for at least some of the participants of the debate was the legitimacy in principle of the use of atomistic conceptions in physics. I will analyze this controversy as a debate about legitimate concrete goals of fundamental research in physics. This disagreement over goals was perceived as immediately relevant to concrete research programs. While this analysis points to a certain continuity with the later realism debate, which has also been analyzed as a controversy over the aims of science, it also permits the diagnosis of some significant differences, as I will try to show in the concluding section.

\section{Puzzles of atomism: Emil Du Bois-Reymond}

Is it a worthwhile aim of physics to search for ultimate explanations of phenomena in terms of the ultimate elements of matter, the atoms? In late 19th century Germany, many articulated skepticism about such a goal. Thus in 1871, Hermann von Helmholtz remarked:

On atoms in theoretical physics, Sir William Thomson aptly says that assuming them can explain no property of bodies that has not been attributed to the atoms themselves beforehand. In assenting to this statement, I do not want to declare myself against the existence of atoms, but only against the ambition to derive the foundations of theoretical physics from purely hypothetical assumptions on the atomic construction [Atombau] of natural bodies. (Helmholtz 1871, p. 45) ${ }^{2}$

\footnotetext{
2 All translations are my own, except where the source indicated in the bibliography is already a translated version. Helmholtz gives no reference to Thomson's statement, but he was probably referring to the latter's remark that "Lucretius's atom does not explain any of the properties of matter without attributing them to the atom itself." (Thomson 1867, pp. 1 f.)
} 
A year later, Helmholtz's friend Emil Du Bois-Reymond went a step further. In his extremely influential lecture, titled 'Über die Grenzen des Naturerkennens' ('On the limits of our knowledge of nature'), he challenged the legitimacy of atomist conceptions. Du Bois-Reymond, already a well-known physiologist and famous for his campaign against vitalism, delivered this speech at the Naturforscherversammlung, the big yearly German scientific congress. He maintained that scientific knowledge was limited in principle, in the sense that there were two puzzles that were out of reach of natural science: First, the ultimate nature of matter and force was strictly unfathomable, and second, the phenomena of thought and consciousness and their relation to physical nature were not explainable by scientific means. His famous conclusion "ignorabimus", "we shall not know", was to become "the catchword for a whole period, the catchword for defeatism in science, the catchword that constituted the delight of all anti-scientific trends of that time", as Philipp Frank later complained. (Frank 1979, pp. 81 f.) $)^{3}$

Du Bois-Reymond's lecture had already caused a stir among his contemporaries. Some of his more materialistically minded colleagues saw in it a selfdenial of science and an unnecessary concession to the churches and other conservative cultural forces. (Cf. Lübbe 1981, pp. 138-142, Anderton 1993, pp. 210226.) But Keith Anderton has convincingly argued that the "ignorabimus" was in fact part of a strategy to create leeway for free scientific research. Helmholtz, Du BoisReymond and others were creating a biomedical research program that was aimed at founding physiology on a solid experimental basis and eliminating its vitalistic elements. (Cf. Lenoir 1982, chap. 5.) For a successful development of their program, they had to steer away from drastic conflict with religious values, as well as from the danger of conflation of their program with the fashionable (and often highly speculative) materialism of the time. Du Bois-Reymond's agnosticism was meant to separate the new physiology from the realm of metaphysics and religion and (especially in the form of his denial of the ultimate knowability of matter) to demarcate it from naïve materialism. (Cf. Anderton 1993, pp. 21-23, 100 f., 219 and passim. $)^{4}$

While Du Bois-Reymond's famous speech is still widely remembered for its announcement of the second of the two principal limitations, regarding the phenomena of thought and consciousness, I shall here be concerned with the first. Here, Du Bois-Reymond was specifically concerned with the concept of the atom. At first, he presents himself as an atomist and mechanicist, identifying all cognition of nature with the reduction of phenomena to motions of atoms that are governed by central forces. (Du Bois-Reymond 1872, pp. $54 \mathrm{f}$.) But although this is the best we can

\footnotetext{
${ }^{3}$ Among the logical positivists, Frank was not alone in his condemnation of Du Bois-Reymond's "Ignorabimus", see Geier 1992, pp. 99-102.

${ }^{4}$ I am grateful to an anonymous referee for calling my attention to Anderton's excellent but unfortunately unpublished dissertation.
} 
do in terms of cognition of nature according to Du Bois-Reymond, and though it seems to fulfill our "need of causality" ("Kausalitätsbedürfnis") at first sight, it ultimately falls short of real cognition ("Erkennen").

The idea according to which the world consists of smallest particles that are imperishable and have always been there and whose central forces generate all motion, is in a sense just the surrogate of an explanation. (Ibid., p. 60.)

Du Bois-Reymond argues that atomistic physics presents atoms and their forces as given, while we would ultimately need an understanding of their nature to satisfy our need for explanation. But attempts to capture the essence of the atom ("es seinem Wesen nach zu begreifen") lead to corpuscular philosophy and to "unsolvable contradictions". (According to Du Bois-Reymond, this does not belittle the fact that in physics and chemistry, the atom is an "extremely useful fiction", ibid.)

$\mathrm{Du}$ Bois-Reymond assumes that the "philosophical atom" that would be required to give an atomistic account of the ultimate nature of matter would have to be bearer of central forces, indivisible, inert, and "in itself effectless". The last requirement presumably demands that the atom stand in no other causal relations than those governed by the central forces and their laws, because if there were any additional effects associated with the atom, then those would again stand in need of an explanation and could not themselves be reduced to atoms and their forces. (Note that this idea is remotely related to Thomson's and Helmholtz's remarks. ${ }^{5}$ ) Now Du Bois-Reymond's confirmation of the contradictory character of this concept can be summed up in three steps.

[i] He claims that if the atom is to have continued existence ("Bestand"), then it must occupy at least a little space. (This is because Du Bois-Reymond regards the atom as a passive substrate and thus sees its occupation of space as the only way in which it could manifest its existence. Cf. Vidoni 1991, p. 123.) But then it is incomprehensible why it should not be further divisible.

[ii] Also, it can only occupy space by exerting a potentially limitless repulsive force at its borders, which contradicts its effectless character.

[iii] The attempt to solve such problems by regarding only the central point as the true substrate and bearer of all forces is likewise rejected by $\mathrm{Du}$ BoisReymond, because then the atom does not really occupy space anymore and this leaves nothing that the central forces could attach to or that could possess inertia. (Du Bois-Reymond 1872, pp. 60 f.)

(In the last step, he is of course referring to the so-called "dynamist" atom, invented by Rudjer Boscovich in 1758.) At the same time, Du Bois-Reymond maintains that an

\footnotetext{
${ }^{5}$ Helmholtz (1871) is referred to in a footnote to Du Bois-Reymond (1872, p. 251, footnote 13) - though on a slightly different point.
} 
atomistic account would be the only thing that could really fulfill our need for causality and provide a satisfactory explanation of the nature of matter. Since he believes he has shown that this prospect is barred by the contradictions of the philosophical atom, he concludes that the essence of matter remains concealed from us by what he regards as a barrier of "transcendental nature" (ibid., p. 62).

Before I turn to my main concern, which is how the consistency challenge to atomism was received and commented on, allow me a few remarks on its possible origins. I am not trying to make the point that Du Bois-Reymond was the originator of the consistency challenge, or even that later commentators on that challenge were thinking of his formulation when they responded to the problems. His lecture simply contains a very explicit formulation of that challenge, and given the great publicity of the lecture, it is not implausible that this formulation exerted some influence on how the challenge was perceived. But in our context, the essential point is just that a consistency challenge to atomism existed and that it was received with attention in some parts of the scientific community. Nonetheless, some observations on the origins of these ideas are helpful for understanding the context of the discussion. In the antithesis of the second antinomy of pure reason, Kant had argued that a composite physical thing could not consist of simple (non-composite) parts, because each of these parts would have to occupy space and therefore itself be composite. (Kant 1781, B 463-470.) Beyond this possible Kantian inspiration (especially for step [i]), there is reason to assume that doubts about the consistency of atomism were somewhat "in the air" in 19th century German academic culture. For example, the criticism that a point atom's supposed lack of spatial extension would conflict with its possession of inertia (step [iii]) had been preceded by a similar objection (that it would conflict with its possession of weight) by Justus von Liebig in his Chemische Briefe of $1844 .{ }^{6}$ And only a year before Du Bois-Reymond, Rudolf Virchow had given a lecture at the Naturforscherversammlung and warned against the folly of criticizing the atom "from the so-called philosophical standpoint" and foregoing this useful concept "for the sake of "ultimate' problems". (Virchow 1871, pp. 24 f., cf. Vidoni 1991, p. 114.) Note also that Du Bois-Reymond uses the phrase "one finds, as is well known" ("Da ergibt sich denn bekanntlich") when he announces the contradictions of atomism (Du Bois-Reymond 1872, p. 60).

One additional likely source of inspiration for Du Bois-Reymond (and others) on this matter deserves special mention. It is the philosophy of Johann Friedrich Herbart, one of whose central theses was that the fundamental metaphysical concepts were enmeshed in irresolvable contradictions, that "concepts are forced upon us by experience, which nevertheless can not be thought" (Herbart 1837, p.

\footnotetext{
${ }^{6}$ Liebig's objection (1844, p. 57) was noted by Gustav Theodor Fechner in his pro-atomist Atomenlehre (1st ed. 1855), which Du Bois-Reymond refers to in a footnote to "Grenzen des Naturerkennens" (cf. Fechner 1864, p. 160, Du Bois-Reymond 1872, pp. 251 f., note 15). Note that Fechner's book includes extensive coverage of his teacher Herbart, of whom to speak shortly.
} 
184). This view was influenced by Herbart's broadly Kantian bend and his fascination with the antinomies, but it was also considerably strengthened by his serious engagement with Eleatic philosophy and its paradoxes. The contradictory concepts not only included such basic metaphysical ones as the concept of a thing, but also concepts of natural philosophy, notably the concept of the atom (ibid., pp. $247 \mathrm{f}$.). Thus Herbart's philosophy could have provided a role model with regard to the remarkable strength of Du Bois-Reymond's thesis, that the contradictions present an insurmountable obstacle.

Also, the effectless character of Du Bois-Reymond's philosophical atom enjoys similarities with Herbart's "simple beings", which form the basis of his natural philosophy (though they are not to be conceived as spatio-temporal atoms but as some kind of monads). In a tract called Theoriae de attractione elementorum principia metaphysica ("Metaphysical foundations of the theory of elementary attraction", published in 1812 and translated into German in 1859), Herbart had argued that if a being $A$ possessed as an attribute a force "that exerts its activity in $B^{\prime \prime}$, that would contradict the simplicity of $A$ (Herbart 1859, pp. 27 ff.) - an argument that may be reflected in Du Bois-Reymond's step [ii].

$\mathrm{Du}$ Bois-Reymond himself mentioned Herbart's metaphysics in an earlier address on Leibniz, calling it a revitalization of monadology "in a more refined guise" (Du Bois-Reymond 1870, p. 33). Generally, Herbart's explicitly anti-idealistic philosophy was an important point of reference in 19th century Germany (especially for all those who found fault with the long-prevailing dominance of German idealism). ${ }^{7}$ In view of the prominence of Herbart's metaphysics, along with some interesting parallels in the argument, it is thus plausible (if not verifiable) that this is where some of Du Bois Reymond's ideas came from.

\section{Intellectual division of labor: Heinrich Hertz}

Instead of exploring the consistency challenge itself or its origins further, I will now concentrate on some of its repercussions with physicists who emphasized atomism's explanatory potential. One of these was Heinrich Hertz, who took up the consistency challenge in a lecture course on the constitution of matter given at the University of Kiel in 1884. Following a list of the explanatory successes of atomism in chemistry and kinetic theory, he addresses the possibility of philosophical objections and lists some possible challenges:

Does matter then occupy the space of an atom continuously or discontinuously? How does this occupied space then differ from empty space,

\footnotetext{
${ }^{7}$ Thus, when Du Bois-Reymond's teacher Johannes Müller proposed the name "organic monads" for cells, he took the trouble to critically treat Herbart's monadology on the same pages. On this and Herbart's influence on Müller and Du Bois-Reymond generally, see Roth and Stiening 2001.
} 
if we abstract from all outer effects? Or is your atom only that space which is occupied by the forces radiating from a punctiform center of force? And if yes, how do you resolve all the difficulties that I encounter with this idea? (Hertz 1884, p. 32.)

Note that in the same context Hertz also defends the use of atoms against the objection that our descriptions of atoms will inevitably use concepts of properties that we derive from experience and re-apply to a context that lies beyond our experience (ibid., pp. 33 f.). This problem was also brought up by Du Bois-Reymond and was closely associated with the philosophical contradictions of atomism (Du Bois-Reymond 1872, pp. 61 f.). However, as I noted above, it is not of essential interest whether Hertz had $\mathrm{Du}$ Bois-Reymond or some other source of the consistency challenge on his mind.

Hertz's response to the philosophical challenges is to suggest a division of labor between physics and philosophy. Physics investigates the facts of nature, philosophy investigates the difficulties that the human intellect encounters when it tries to grasp these facts (Hertz 1884, p. 32). Hertz claims that both projects can be pursued independently:

The value of a fact's cognition is not decreased by the difficulty that the intellect has in finding a conceptually consistent formulation of it. (Ibid.)

At first sight, this apparent indifference toward difficulties concerning the consistency of basic concepts seems remarkable. Should conceptual problems not be more worrisome to the practicing physicist? In his famous Principles of Mechanics (1894), the same Heinrich Hertz later undertook a reconceptualization of mechanics in order to eliminate the concept of force, which he accused of producing "logical cloudiness". (Hertz 1894, pp. 6-10, esp. p. 8.) There, he backed up his own reconceptualization project with a picture theory of physical knowledge. Pictures contain our conceptions ("Vorstellungen") of the physical world, they specify the hidden agents behind the observable phenomena (cf. Heidelberger 1998, pp. 18-23). Hertz's first and foremost requirement for a picture was that it must not contradict the laws of thought. One might therefore be surprised about the carefree attitude towards the conceptual problems of atomism that Hertz displayed in his earlier lectures. But a plausible interpretation is that Hertz thought that the "difficulty that the intellect has in finding a conceptually consistent formulation" of atomism did not warrant the conclusion that the atomist picture was actually logically contradictory.

Hertz's 1884 remarks on atomism and his later picture theory have in common that in both cases, Hertz allows that different pictures of the same physical reality are possible: "Different pictures of the same objects are possible and they can vary in different respects." (Hertz 1894, p. 2, cf. Schiemann 1998.) The same three constraining requirements for a picture as developed in the Principles of Mechanics are 
already formulated in the context of his earlier remarks on atomism as constraints on the "properties that we are allowed to attribute to matter": they must capture the perceptible facts, they must not contain logical contradictions, and they must be useful (Hertz 1884, p. 35). Hertz was obviously optimistic that the atomist picture would fulfill these requirements for its usefulness in physics, even if the philosophical part of his divided project should prove unable to come up with a clear understanding of the atom.

If, for example, I should not be allowed to speak of the diameter of an atom in the proper sense, still that which I call the diameter of an atom for a certain gas retains its meaning: It is a length with the aid of which I can establish a relationship between the thermal conductivity of the gas, its internal friction, its dielectric constant and its index of refraction. (Ibid.)

Hertz considered it possible to regard the physicist's atom as mere auxiliary fiction, but he insisted that physics is not obliged to adopt this restricted point of view (see below, section 6). Most importantly, he was confident that the "physical" side of atomism could be separated from the "philosophical", and that therefore the consistency challenge would remain inconsequential for the project of developing an atomistic picture of matter.

\section{Only a picture: Ludwig Boltzmann (I)}

Hertz's stance might be understood as an evasion of the consistency challenge that is achieved by giving up the aim of providing an unequivocal clarification and explanation of the constitution of matter as an essential part of the atomistic research program. Another physicist who at times adopted such a stance was Ludwig Boltzmann. In the middle of the second volume of his Lectures on the Principles of Mechanics, we find the following remark:

If I say that the mechanical pictures can be capable of [elucidating such concepts as entropy], I do not thereby mean to claim that the position and motion of material points in space was something whose most simple elements were completely explainable. To the contrary, it is not at all possible to explain the ultimate elements of our knowledge; for to explain means to reduce to things better-known and simpler, and therefore whatever everything is reduced to must remain forever unexplainable. (Boltzmann 1897/1904, vol. 2: p. 137)

But at other times, Boltzmann tackled the problem of apparent conceptual difficulties concerning the basic notions of physics more radically. He employed a picture theory not unlike that which Hertz used for his campaign against the notion of force. (Cf. D'Agostino 1990, Blackmore 1995b, pp. 69-74 and de Regt 1999.) Boltzmann's view, 
which he regarded as exemplified in the work of the admired James C. Maxwell, was that physical theory provided "a mere picture [Bild] of nature [...] which at the present allows one to give the most uniform and comprehensive account of the totality of phenomena" (Boltzmann 1899, p. 83). Though physical pictures of course partially correspond to reality, they inevitably add extraneous elements. This makes the application of pictures somewhat risky, as Boltzmann pointed out in his paper on 'The Indispensability of Atomism in Natural Science':

Finally, I should like to go further and almost venture the assertion that it lies in the nature of a picture to have to add certain arbitrary features for the purpose of representation [Abbildung], and that strictly speaking one goes beyond experience as soon as one infers from a picture adapted to certain facts to even a single new fact. (Boltzmann 1897, p. 47)

Boltzmann's picture theory has sometimes been seen as an epistemological concession in his debate with Mach (cf. Blackmore 1995b, 1999), but it served more than one argumentative purpose for him. It also alleviated worries about basic conceptual problems, which were an important concern to him. In his inaugural lecture in Leipzig in 1900, he declared that "the old Kantian antinomy opposing infinite divisibility of matter to atomistic constitution still keeps science in suspense" (Boltzmann 1900, p. 145). He explained the relevance of his picture theory to this problem in his lecture of 1899 on 'The Development of the Methods of Theoretical Physics in Recent Times':

Many questions that used to appear unfathomable thus fall away of themselves. How, it used to be said, can a material point which is only a mental construct, emit a force, how can points come together and furnish extension, and so on? Now we know that both material points and forces are mere mental pictures. The former cannot be identical with something extended, but can approximate as closely as we please to a picture of it. The question whether matter consists of atoms or is continuous reduces to the much clearer one, whether [the idea of enormously many particulars or the idea of] the continuum is able to furnish a better picture of the phenomena. (Boltzmann 1899, p. 91) ${ }^{8}$

At first sight, this quotation might make it look like Boltzmann attributed equal chances of success to an atomist picture and a possible rivaling continuous picture of matter. His attitude was quite a different one, however. In several places, he developed a sophisticated argument in order to show that all continuous pictures in physics ultimately presupposed an atomistic conception. To Boltzmann, this was evident from their reliance on continuous functions in real analysis. The

\footnotetext{
8 The words in squared brackets appear in the German original, but not in the translation in McGuinness's edition.
} 
mathematical continuum, he thought, was only understandable as a limit-transition that always had to start from a partition into a finite number of elements. So the big difference between atomistic and continuous conceptions, Boltzmann concludes, is that continuous pictures conjecture that the best representation of nature is only reached with the actual limit-transition and not at some earlier, finite stage. In his judgment, this conjecture is unwarranted; therefore atomistic pictures contain fewer arbitrary assumptions. But it is not only this relative advantage that speaks in favor of atomism. To Boltzmann, his conviction that "all infinite in nature never means anything other than a transition to the limit" (which he had already announced in his famous 1877 paper containing the proof of Boltzmann's equation, $S=k \log W$, cf. Boltzmann 1877, pp. 167 f.) meant that atomism is "inseparable from the concept of the continuum" (Boltzmann 1897, p. 44). The atomist picture is not only preferable, but conceptually indispensable. ${ }^{9}$

Boltzmann's intention in presenting this argument is clearly to turn the tables on the so-called phenomenological position of Wilhelm Ostwald and others, who criticized atomism as an unwarranted assumption and demanded that physics simply pursue the most economical presentation of empirical facts by means of differential equations. For Boltzmann, the phenomenological approach also lacked the explanatory force of atomistic pictures, which the latter achieved by regarding the finite elements or atoms as hypothetical bearers of a limited number of basic properties. This comes to the fore when he compares the phenomenologists to Nicolas Lemery, a baroque chemist who had introduced the practice of liberally attributing new properties to atoms whenever it served the aim of explaining a particular chemical fact:

Current phenomenology has thus quite returned to the standpoint of Lemery [...] who likewise did not hesitate to ascribe the most complicated properties to atoms, so soon as this offered some explanation of the facts known to him; only we fail to notice this because we hide our heads in differential equations as an ostrich in sand. (Boltzmann 1897, p. 51, note 4)

In short, Boltzmann used conceptual considerations in an attempt to turn the tables on the phenomenological anti-atomists and reveal the atomistic picture as more basic. But as we shall see, he had an even more daring theoretical defense of the atomistic conception up his sleeve; and this one turned the tables on Du BoisReymond.

\footnotetext{
${ }_{9}$ This line of thought is most extensively elaborated in Boltzmann 1897. For an analysis of this argument, see also Wilholt 2002.
} 


\section{Puzzles of anti-atomism: Boltzmann (II)}

When Boltzmann had become Mach's successor in Vienna, he gave a lecture course on natural philosophy. ${ }^{10}$ It contains a highly original defense of atomism that starts with the presentation of a mechanical puzzle. (Boltzmann 1906, pp. 92 f., pp. 199 f.) He does not indicate any specific sources of this puzzle, but he does mention that it had been investigated by an artillery officer called "Vega". In fact, it can be found in the third volume of the Lectures on Mathematics of the Slovenian mathematician Georg von Vega (von Vega 1788, pp. 505-512). Vega in turn mentions Leonard Euler as the originator of the puzzle.

In his Mechanics of 1736, Euler had sought to determine the movement of a point mass $A$ that moves straight towards a center of force $S$ to which it is attracted. (Euler 1736, propositio 80, esp. $§ 655$, cf. also propositio 32.) He had conceived of this setting as a limiting case of the general form of motion governed by a single center of force, elliptical motion. If the small axis of the ellipse becomes infinitely small, and the ellipse infinitely eccentric, then one apsis of the ellipse moves infinitely close to the focus at $S$. In the limiting case, $A^{\prime}$ s starting point and $S$ form the end-points of a straight line. The result is that $A$ will move toward $S$ in a straight line, but upon arrival will be instantaneously reflected and will move backwards toward the starting point.

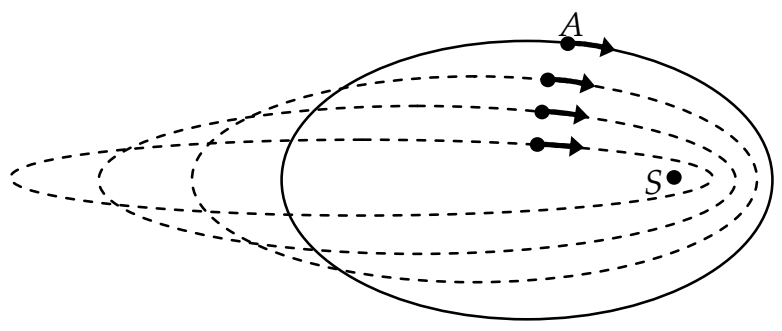

limiting case

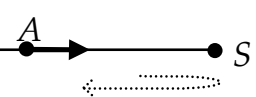

Figure 1: Euler's calculation

In a scholion, Euler had admitted the counter-intuitive appeal of this conclusion: "For it hardly becomes clear to reason why the body with its infinitely large velocity, which it has acquired when at [S], should progress into another direction [...]." However, Euler thinks, "here one has to trust the calculation rather than our judgment and declare that we do not deeply comprehend a leap if it occurs from the infinite to the finite" (Euler 1736, p. 88). ${ }^{11}$

\footnotetext{
${ }^{10}$ The course survives in form of his own fragmentary notes and an unknown student's elaboration, both of which have been edited by Ilse Fasol-Boltzmann (Boltzmann 1906).

${ }^{11}$ This remark is contained in Euler's discussion of a different setting (assuming a $1 / r$ force law), but is immediately followed by a reference to the case we are dealing with here, by which, as Euler claims, the quoted remark is confirmed even more strongly.
} 
Vega declared, "it is impossible that this claim is correct" (Vega 1788, p. 507), for reasons similar to the conflicts with intuition described by Euler. Vega preferred to calculate the motion of $A$ right through $S$ by means of integration, starting from the inverse square force law. Boltzmann, in his presentation of Vega's treatment, tacitly supplements it with a tiny sphere around $S$ where the attractive force is suspended, in order to avoid division by zero.

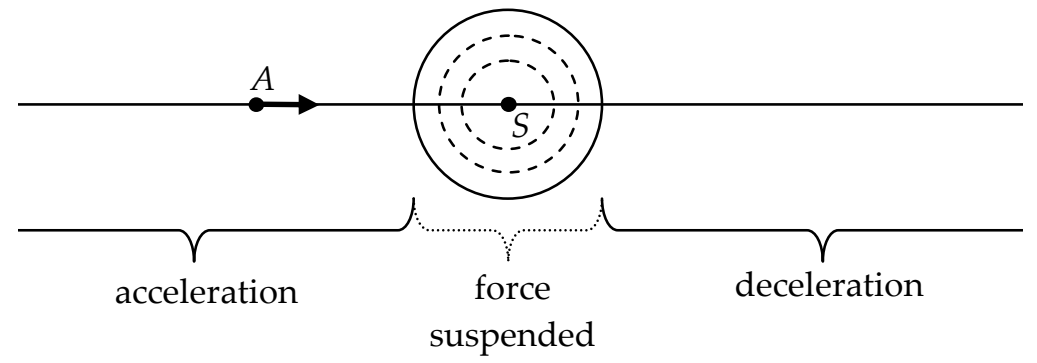

limiting case

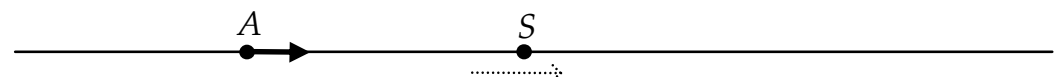

Figure 2: Vega's calculation (as corrected by Boltzmann)

He then presents the case as a paradox. If, in Euler's calculation, the small axis becomes infinitely small, and, in Vega's calculation, the sphere around $S$ becomes infinitely small, then they both converge to a treatment of exactly the same setting, but with directly opposite results, and it becomes impossible to decide which is the correct one. To Boltzmann, this problem only arises from the conceptions of continuity and infinitary reasoning involved:

In fact, if we never adopt anything infinite, if we only calculate with finite magnitudes that can be arbitrarily large, we never get to a contradiction. [...] But if $A$ coincides with $S$ and if Newton's law is valid till coincidence, [...] then I enter into set theory, into the really infinite, into the ultimate number $\omega$, and I encounter contradictions. [...]

It is the core of my definition that matter must consist of a discrete number of material points. We must conceive of it as composed of a finite number of discrete points if we are to be capable of drawing secure conclusions. [...] If we have a discrete conception of all this, we always obtain unambiguous results. [...] If we allow an absolute continuum, this does not hold anymore. Expressed in our philosophical language, this is in effect [eigentlich] the proof of the atomistic constitution of matter. (Boltzmann 1906, p. 200)

Ultimately, Boltzmann thus reverses the argumentative situation that the consistency challenge, as originally formulated by Du Bois-Reymond and others, had created. It

He mentions a leap from the infinite to the finite because according to his calculation, $A$ momentarily acquires an infinite velocity at $S$. 
is not atomism but the non-atomistic, continuous conception that leads to conceptual conflicts. Of course, Boltzmann's remarks only make sense if they are considered as an argument in favor of an atomism not just of matter (the constitution of matter is not really at issue in this specific paradox) but of nature in general. In another lecture, he even suggested that one should regard time as a succession of "finite moments" (ibid., p. 189).12 For Boltzmann, only thoroughly atomistic conceptions could ultimately avoid the conceptual conflicts that arose from infinitary reasoning. The conflicting conclusions displayed in the Euler-Vega paradox seriously challenge the usefulness of the underlying continuous conception of nature, because "the purpose of thinking is to be able to unambiguously draw conclusions everywhere" (ibid., p. 200). Atomism, in contrast, steers clear of dubious infinitary notions. It thereby avoids contradictions and emerges from Boltzmann's lectures as the clearly preferable research program. As he put it in his own shorthand notes on the EulerVega paradox: "That is my proof that nature must be constructed atomistically" (ibid., p. 92). (A proof, to be sure, that probably did not have any impact, given that Boltzmann never published his remarks on the paradox.)

\section{When realism made a difference}

There can be no doubt that for Boltzmann an important goal of fundamental research in physics was to find the correct answer to "the query whether matter is to be conceived as continuous or as composed of discrete constituents (of very many but not mathematically speaking infinitely many individuals)" (Boltzmann 1904, p. 163), as he put it in his 1904 address to the Scientific Congress in St. Louis. He goes on to point out: "This precise question is of too much topical interest to science to be completely ignored, but we cannot discuss it without at the same time touching on even deeper problems such as the nature of causality, matter, force and so on." (Ibid.) Boltzmann thus embraced the investigation of the constitution of matter as part of the goals of physics. He was aware that the consistency challenge was a threat to this goal. Three decades earlier, Du Bois-Reymond had regarded the consistency challenge in the same way - as an argument that forbade the broadening of atomism

\footnotetext{
${ }^{12}$ Remarks on discontinuous time can also be found in footnote 4 in $(1897$, pp. 51 f.) and in a letter to Franz Brentano from January 1905 (Blackmore 1995a, p. 125). His comments are less specific with regard to a conceivable discreteness of space, though he considers the possibility of conceiving of a point of space as a "very small object with very little extension in all directions" in the natural philosophy lecture course (1906, p. 210). He had already earlier declared the conception of the material atom as possessing a certain finite extension "the more natural one" (1897, p. 43), but whether he ultimately aimed at a wholesale criticism of point-like particle models in physics is unclear. He kept using them himself and once observed that "the view of atoms as material points and of forces as functions of their distance is no doubt provisional but must at present be retained failing a better one" (ibid., p. 52).
} 
into a research program for ultimate explanations and that even posed a principal limit to our understanding of matter.

It used to be said that methodological discussion is reasonably limited to debates over the appropriate means to reach the shared goals of science, and that the goals themselves lie beyond the limits of rational discourse (see for example Reichenbach 1938, p. 12). But as Larry Laudan has pointed out, some limited possibilities for reasoned criticism and defense of goals do exist. In particular, a forceful argument against a goal can be made by demonstrating that it is unrealizable (1984, pp. 51-53). The arguments of Boltzmann and Du Bois-Reymond can plausibly be located on that axiological level of discourse, since they are concerned with the acceptability of concrete goals of physical research. From the perspective of Laudan's observation, it is thus not surprising that both authors ultimately tried to establish impossibility claims - in Du Bois-Reymond's case, the impossibility of an ultimate understanding of matter, in Boltzmann's case, the impossibility of a physics that allows the drawing of reliable conclusions without an underlying, well-understood finite conception of nature.

In Heinrich Hertz's 1884 lectures we can find a markedly different attitude. Hertz clearly did perceive the disagreement over the goals of physics. In a passage discussing the possibility of regarding atoms as mere mathematical fictions, he observes:

Many physicists hold that in fact the task of physics does not go beyond that, and that the theory of the constitution of matter can only be regarded from that standpoint. [...] I say: Physics can confine itself to seeing things that way, and still be in its full right, but physics is not forced to confine itself that way. (Hertz 1884, p. 35.)

Hertz clearly thought that the atomistic program could unfold its major benefits either way, whether atoms were regarded as real or as mere computational devices. The diverging conceptions of the task of physics would then remain largely inconsequential for concrete research programs in physics, given that even the critics conceded that atoms could be useful fictions. (Du Bois-Reymond not only accepted but welcomed the atomist picture for restricted uses-as long as no ultimate explanation of the nature of matter was claimed. ${ }^{13}$ ) It is thus not surprising that Hertz was willing to leave the discussion of the consistency challenge to the philosophers.

\footnotetext{
${ }^{13}$ Among the later phenomenological opponents of atomism, it was likewise often admitted that "the atom may at least remain a means to represent the phenomena" (Mach 1882, p. 229). However, it was sometimes claimed that atomism as a research program was bound to lead physics astray, because it distracted from the search for the simplest representation of the phenomena. Since the phenomenologists saw no warrant for the hope that atomism could be successfully carried forth beyond its past successes, adherence to the program was feared to make physicists "careless"; such that it was therefore "dangerous to say that atoms exist" (Helm 1898, p. 361).
} 
Boltzmann could ultimately not agree. For him, the conceptual problems of the constitution of matter, "of which one used to say that they were of no concern to the scientist and should be handed over entirely to philosophy" (1904, p. 163), cannot be separated from the physical research program. "[O]nce we examine the simplest elements, where would be the boundary between science and philosophy at which we could stop?" (Ibid., p. 164.) In Boltzmann's view, his concrete physical research program did not remain unchallenged by the axiological disagreement; therefore, a stronger involvement in the debate over the concrete goals of physics was finally inevitable for him. Where his picture-theory response to anti-atomism invoked shared goals (creating an adequate picture on the basis of as few arbitrary assumptions as possible), in his final argument for atomism he directly defended the contested goal of achieving an adequate understanding of the ultimate elements of physical reality.

I would like to round out this paper with a comparison of the consistency challenge with the 20th century debate over scientific realism. A manifest point of comparison is that the realism debate can be and has been understood as a disagreement over the goals of science: "At its core, realism is a normative doctrine about what the aims or values of science ought to be. Specifically, the realist maintains that the goal of science is to find ever truer theories about the natural world." (Laudan 1984, p. 106.) ${ }^{14}$ According to this analysis, underlying the realism debate is an axiological disagreement over this general goal of science. In contrast, Du Bois-Reymond, Hertz and Boltzmann were concerned with one very specific goal of physics, namely of explaining the nature of matter by achieving an understanding of its ultimate elements. This is why the arguments of Du Bois-Reymond and Boltzmann were much more specifically concerned with details of the specific physical conceptions at issue than were most of the arguments in the 20th century realism debate.

That said, it has to be acknowledged that at some points in the 20th century debate, the discussion did concentrate on very specific physical conceptions. In particular, some have argued that a realistic understanding of the physics of the quantum world can in principle not be achieved, and that this spoiled the prospects for a thoroughgoing scientific realism (cf. van Fraassen 1982, Peres 1985). Especially the technical results of John Bell have been seen by many as indicating a limitation to scientific realism. (See Fine 1986, chap. 9, for critical discussion.) Such use of the Bell inequalities echoes the earlier consistency challenge to atomism in the sense that both attempt to utilize an impossibility proof in order to establish some kind of "lower limit" to our elucidation of the workings of nature. The modern realism debate has

${ }^{14}$ Cf. van Fraassen 1980, p. 8, for a similar definition of scientific realism. For the purposes of this paper, this is an acceptable characterization of the core issue of the 20th century debate over scientific realism, though it must be conceded that typically, a realist's claims would extend not only to the aims of science but also to past and current achievements with regard to these aims (cf. Kitcher 1993, p. 150). 
thus tied in with a debate about particular goals of fundamental research in physics and may do so again in the future. Still, the mainstream of the modern discussion, which has concentrated on such issues as the underdetermination of theory by data, the pessimistic induction, or the notion of inference to the best explanation, has by and large been directly concerned with the general aims of science.

Another difference between the consistency challenge and the larger part of the 20th century realism debate is that the latter is very often regarded as inconsequential with respect to the concrete procedures of science. Ernest Nagel concluded his classic study of realism and instrumentalism with the observation "that when the two apparently opposing views on the cognitive status of theories are each stated with some circumspection, each can assimilate into its formulations not only the facts concerning the primary subject matter explored by experimental inquiry but also all the relevant facts concerning the logic and procedure of science." (Nagel 1961, p. 152.) $)^{15}$

In contrast, both Du Bois-Reymond and Boltzmann, when attempting to prove that certain concrete goals were unrealizable, also believed that their insights should bear on the course of inquiry. At the same time, the modern attitude of neutrality is very similar to Hertz's view. Underlying this idea of neutrality is the belief that in the respective cases at issue, two competing sets of goals can both be consistent with one and the same research program or set of research programs. In this sense, a reference to Hertz's attitude can serve to underscore the accepted view that the modern realism debate is anticipated in 19th century disputes over atomism. However, we have seen that some contributions to these disputes also exemplify an attitude that is different from Hertz's and also (in my impression) from the prevailing attitude towards the realism issue since the 20th century. It differs in that it is specifically concerned with a disagreement over concrete goals of fundamental research in physics and in that it perceives this disagreement as bearing on concrete research programs. The modern attitude turns the realism issue into a question about how physics should be interpreted. Du Bois-Reymond and Boltzmann, despite all differences in opinion, would have concurred that the question was how physics should be done and what its limits are.

\footnotetext{
${ }^{15}$ A similar attitude of neutrality is also implicit in the later debate between realism and constructive empiricism. This results from van Fraassen's concept of theory acceptance, which is his anti-realist Ersatz for the realist's belief in a theory. Acceptance in van Fraassen's sense includes not only belief in the theory's observable consequences but also a commitment to use the theory to make predictions, give explanations, design experiments, etc. (van Fraassen 1980, pp. 12 f.). The constructive empiricist's acceptance of a theory involves no less commitment to the corresponding research program than the realist's belief.
} 


\section{References}

Anderton, K. M. (1993). The Limits of Science: A Social, Political and Moral Agenda for Epistemology in Nineteenth Century Germany. Dissertation. Cambridge, Massachusetts: Harvard University.

Blackmore, J. (1995a). Ludwig Boltzmann: His Later Life and Philosophy, 1900-1906, Book One: A Documentary History. Dordrecht etc.: Kluwer.

Blackmore, J. (1995b). Ludwig Boltzmann: His Later Life and Philosophy, 1900-1906, Book Two: The Philosopher. Dordrecht etc.: Kluwer.

Blackmore, J. (1999). Boltzmann and Epistemology. Synthese, 119, 157-189.

Boltzmann, L. (1877). Über die Beziehung zwischen dem zweiten Hauptsatze der mechanischen Wärmetheorie und der Wahrscheinlichkeitsrechnung resp. den Sätzen über das Wärmegleichgewicht. In F. Hasenöhrl (ed.), Wissenschaftliche Abhandlungen von Ludwig Boltzmann, Vol. 2 (pp. 155-220). Leipzig: Barth 1909.

Boltzmann, L. (1897/1904). Vorlesungen über die Prinzipe der Mechanik, Vols. I and II. Reprint. Darmstadt: Wissenschaftliche Buchgesellschaft 1974.

Boltzmann, L. (1897). On the Indispensability of Atomism in Natural Science. In: B. McGuinness (ed.), L. Boltzmann, Theoretical Physics and Philosophical Problems: Selected Writings (pp. 41-53). Dordrecht: Reidel 1974.

Boltzmann, L. (1899). On the Development of the Methods of Theoretical Physics, In: B. McGuinness (ed.), L. Boltzmann, Theoretical Physics and Philosophical Problems: Selected Writings (pp. 77-100). Dordrecht: Reidel 1974.

Boltzmann, L. (1900). On the Principles of Mechanics. In: B. McGuinness (ed.), L. Boltzmann, Theoretical Physics and Philosophical Problems: Selected Writings (pp. 129-152). Dordrecht: Reidel 1974.

Boltzmann, L. (1904). On Statistical Mechanics. In: B. McGuinness (ed.), L. Boltzmann, Theoretical Physics and Philosophical Problems: Selected Writings (pp. 159-172). Dordrecht: Reidel 1974.

Boltzmann, L. (1906). Principien der Naturfilosofi: Lectures on Natural Philosophy 19031906. Ed. by Ilse M. Fasol-Boltzmann. Berlin etc.: Springer 1990.

D'Agostino, S. (1990). Boltzmann and Hertz on the Bild-Conception of Physical Theory. History of Science, 28, 380-398.

De Regt, H. (1999). Ludwig Boltzmann's Bildtheorie and Scientific Understanding. Synthese, 119, 113-134.

Du Bois-Reymond, E. (1870). Leibnizische Gedanken in der neueren Naturwissenschaft. In: S. Wollgast (ed.), E. Du Bois-Reymond, Vorträge über Philosophie und Gesellschaft (pp. 25-53). Hamburg: Meiner 1974. 
Du Bois-Reymond, E. (1872). Über die Grenzen des Naturerkennens. In: S. Wollgast (ed.), E. Du Bois-Reymond, Vorträge über Philosophie und Gesellschaft (pp. 54-77). Hamburg: Meiner 1974.

Euler, L. (1736). Mechanica sive motus scientia analytice exposita. Ed. by P. Stäckel. Leonardi Euleri Opera Omnia, Ser. 2, Vol. 1. Leipzig \& Berlin: Teubner 1912.

Fechner, G. T. (1864). Ueber die physikalische und philosophische Atomenlehre. 2nd ed. Leipzig: Mendelssohn.

Fine, A. (1986). The Shaky Game: Einstein, Realism and the Quantum Theory. Chicago etc.: University of Chicago Press.

Frank, P. (1979). Albert Einstein: Sein Leben und seine Zeit. Braunschweig: Vieweg.

Geier, M. (1992). Der Wiener Kreis. Reinbek: Rowohlt.

Heidelberger, M. (1998). From Helmholtz's Philosophy of Science to Hertz's Picture Theory. In: D. Baird, R. I. G. Hughes and A. Nordmann (eds.), Heinrich Hertz: Classical Physicist, Modern Philosopher (pp. 9-24). Dordrecht: Kluwer.

Helm, G. (1898). Die Energetik nach ihrer geschichtlichen Entwickelung. Leipzig: Veit.

Helmholtz, H.v. (1871). Zum Gedächtniss an Gustav Magnus. In: H. v. Helmholtz, Vorträge und Reden, vol. 2, 4th ed. (pp. 33-51). Braunschweig: Vieweg 1896.

Herbart, J. F. (1837). Lehrbuch zur Einleitung in die Philosophie [1st ed. 1813, 4th ed. 1837]. Ed. by W. Henckmann. Hamburg: Meiner 1993.

Herbart, J. F. (1859): Die metaphysischen Anfangsgründe der Theorie der ElementarAttraction. Transl. by K. Thomas. Berlin: Herbig.

Hertz, H. (1884). Die Constitution der Materie: Eine Vorlesung über die Grundlagen der Physik aus dem Jahre 1884. Ed. by A. Fölsing. Berlin etc.: Springer 1999.

Hertz, H. (1894). Die Prinzipien der Mechanik in neuem Zusammenhange dargestellt. Reprint. Darmstadt: Wissenschaftliche Buchgesellschaft 1963.

Howard, D. (forthcoming). Physics and the Philosophy of Science at the Turn of the Twentieth Century. http://www.nd.edu/ dhoward1/Phil-Phys-1900.pdf

Kant, I. (1781). Kritik der reinen Vernunft. Ed. by R. Schmidt. Hamburg: Meiner 1993.

Kitcher, P. (1993). The Advancement of Science: Science without Legend, Objectivity without Illusions. New York etc.: Oxford University Press.

Laudan, L. (1984). Science and Values: The Aims of Science and Their Role in Scientific Debate. Berkeley etc.: University of California Press.

Lenoir, T. (1982). The Strategy of Life: Teleology and Mechanics in Nineteenth Century German Biology. Dordrecht: Reidel.

Liebig, J.v. (1844). Chemische Briefe. Heidelberg: Winter.

Lübbe, H. (1981). Wissenschaft und Weltanschauung: Ideenpolitische Fronten im Streit um Emil Du Bois-Reymond. In: G. Mann (ed.), Naturwissen und Erkenntnis im 19. Jahrhundert: Emil Du Bois-Reymond (pp. 129-148). Hildesheim: Gerstenberg. 
Mach, E. (1882). Die ökonomische Natur der physikalischen Forschung. In: E. Mach, Populär-Wissenschaftliche Vorlesungen. 2nd ed. (pp. 208-236). Leipzig: Barth 1897.

Nagel, E. (1961). The Structure of Science: Problems in the Logic of Scientific Explanation.

New York etc.: Harcourt, Brace \& World.

Niiniluoto, I. (2002). Critical Scientific Realism. Oxford etc.: Oxford University Press.

Nye, M. J. (1976). The Nineteenth-Century Atomic Debates and the Dilemma of an

'Indifferent Hypothesis'. Studies in History and Philosophy of Science, 3, 245-268.

Peres, A. (1985). Einstein, Gödel, Bohr. Foundations of Physics, 15, 201-205.

Popper, K. R. (1956). Three Views Concerning Human Knowledge. In: K. R. Popper, Conjectures and Refutations. 3rd ed. (pp. 97-119). London: Routledge \& Kegan Paul 1969.

Reichenbach, H. (1938). Experience and Prediction: An Analysis of the Foundations and the Structure of Knowledge, Chicago and London: University of Chicago Press.

Roth, U. and G. Stiening (2001). “Um Mitternacht den Sonnenschirm gebrauchen”: Zur Herbart-Rezeption bei Johannes Müller, Emil Du Bois-Reymond und Hermann von Helmholz. In: A. Hoeschen and L. Schneider (eds.), Herbarts Kultursystem: Perspektiven der Transdisziplinarität im 19. Jahrhundert (pp. 203-228). Würzburg: Königshausen und Neumann.

Schiemann, G. (1998). The Loss of World in the Image: Origin and Development of the Concept of Image in the Thought of Hermann von Helmholtz and Heinrich Hertz. In: D. Baird, R. I. G. Hughes and A. Nordmann (eds.), Heinrich Hertz: Classical Physicist, Modern Philosopher (pp. 25-38). Dordrecht: Kluwer.

Thomson, W. (1867). On Vortex Atoms. In: J. Larmor (ed.), Mathematical and Physical Papers, vol. 4 (pp. 1-12), Cambridge: Cambridge University Press 1910.

van Fraassen, B. C. (1980). The Scientific Image. Oxford: Oxford University Press.

van Fraassen, B. C. (1982). The Charybdis of Realism. Epistemological Implications of Bell's Inequality. Synthese, 52, 25-38.

Vidoni, F. (1991). Ignorabimus! Emil Du Bois-Reymond und die Debatte über die Grenzen wissenschaftlicher Erkenntnis im 19. Jahrhundert. Frankfurt a. M. etc.: Lang.

Virchow, R. (1871). Die Aufgabe der Naturwissenschaften in dem neuen nationalen Leben Deutschlands. Berlin: Franz Duncker.

Vega, G.v. (1788). Vorlesungen über die Mathematik, vol. 3. 4th ed. Vienna: Tendler 1818. Wilholt, T. (2002). Ludwig Boltzmann's Mathematical Argument for Atomism. In: M. Heidelberger and F. Stadler (eds.): History of Philosophy of Science - New Trends and Perspectives (=Vienna Circle Institute Yearbook 9/2001) (199-211). Dordrecht: Kluwer. 